\title{
INSUBORDINAÇÃO CRIATIVA NAS ESCOLAS: TECNOLOGIAS DIGITAIS NAS AULAS DE MATEMÁTICA
}

\section{CREATIVE INSUBORDINATION IN SCHOOLS: DIGITAL TECHNOLOGIES IN MATHEMATICS CLASSES}

\author{
Maria Teresa Zampieri ${ }^{1}$ \\ Universidade Estadual Paulista "Júlio de Mesquita Filho" /Departamento de Educação \\ Matemática / maite.zampieri@gmail.com \\ Tiago Giorgetti Chinellato \\ Universidade Estadual Paulista "Júlio de Mesquita Filho" /Departamento de Educação \\ Matemática / tiago.giorgetti@gmail.com
}

\author{
Sueli Liberatti Javaroni \\ Universidade Estadual Paulista "Júlio de Mesquita Filho" /Departamento de \\ Matemática / suelili@fc.unesp.br
}

\section{Resumo}

O objetivo deste artigo é discutir atitudes de insubordinação criativa de dois professores de Matemática que participaram de cursos de extensão universitária, ofertados por um projeto temático. Esse projeto tem a colaboração de alunos de iniciação científica, mestrado e doutorado, professores universitários e da Educação Básica. Ele vem sendo desenvolvido em seis regiões dentro do Estado de São Paulo. Nesse artigo, o contexto abordado se refere a duas delas, uma na região noroeste do estado e a outra na região do Vale do Paraíba, cujos cursos desenvolvidos são cenários de duas pesquisas de doutorado vinculadas a esse projeto, que seguem uma abordagem metodológica qualitativa. Os procedimentos metodológicos se pautaram na aplicação de atividades experimentais com um software dinâmico, videogravações, aplicação de questionários e diários de campo. A partir da análise dos dados aqui apresentados, conclui-se que a mobilização dos professores para utilizarem as tecnologias digitais, aliada ao apoio da gestão escolar ou de pesquisadores, podem propiciar o surgimento de aulas que oportunizam ao aluno desempenhar o papel central em seu processo de aprendizagem. Para tal, foi necessário que professores, gestores e pesquisadores desconsiderassem algumas diretrizes ou procedimentos, os quais apresentaram obstáculos para o desenvolvimento dessas aulas.

Palavras-chave: Educação Matemática. Tecnologias Digitais. Ensino e Aprendizagem de Matemática. GeoGebra.

\footnotetext{
1 Mestre em Educação Matemática. UNESP, Rio Claro, São Paulo, Brasil. E-mail: maite.zampieri@gmail.com. Bolsista da Fundação de Amparo à Pesquisa do Estado de São Paulo (FAPESP), processo \# 2014/27.166-9. As opiniões, afirmações e conclusões ou recomendações expressas nesse material são de responsabilidade dos autores, e não refletem necessariamente a visão da FAPESP.
} 


\section{Abstract}

The purpose of this article is to discuss attitudes of creative insubordination of two Mathematics teachers who participated in university extension courses, offered by a thematic project. This project has the collaboration of students of scientific initiation, master's and doctorate, university professors and Basic Education. It has been developed in six regions within the State of São Paulo. In this article, the context covered refers to two of them, one in the northwest region of the state and the other in the Vale do Paraíba region, whose developed courses are scenarios of two doctoral researches linked to this project, which follow a qualitative methodological approach. The methodological procedures were based on the application of experimental activities with dynamic software, video recordings, application of questionnaires and field diaries. Based on the analysis of the data presented here, it is concluded that the motivation of teachers to use digital technologies, together with the support of school management and researchers, can foster the emergence of classes that allow students to play the central role in their learning process. For this, it was necessary that teachers, managers and researchers disregard some guidelines or procedures, which presented obstacles to the development of these classes.

Keywords: Mathematics Education. Digital Technologies. Teaching and Learning of Mathematics. GeoGebra.

\section{Introdução}

Já faz mais de duas décadas que a articulação entre tecnologias digitais (TD) e processos de ensino e aprendizagem da Matemática vem sendo amplamente debatida na comunidade acadêmica, especialmente dentro do âmbito da Educação Matemática. Pesquisas como as de Bairral (2016), Borba e Penteado (2010), Borba e Villarreal (2005), Fernandes e Viseu (2011), Rosa, Pazuch e Vanini (2012), Osta (1998), entre outras, ressaltam potencialidades do uso das TD para abordar conteúdos matemáticos.

Mesmo diante desse interesse pelas TD, e pelo fomento desse uso em aulas de Matemática que tais pesquisas buscam concretizar, ainda são poucos os professores que trabalham com elas em suas aulas. Tal fato é justificado por questões que envolvem por vezes a própria formação inicial e continuada dos professores, bem como as condições de infraestruturas dos laboratórios de informáticas, as condições de trabalho docente, de profissionalização da carreira, ou seja, porque as políticas públicas voltadas para esse propósito não atingem os pressupostos estabelecidos (CHINELLATO, 2014; OLIVEIRA, 2014; PERALTA, 2015). Essa constatação já havia sido feita por Borba e Penteado $(2010)^{2}$ no início da década passada, e continua sendo feita por pesquisas realizadas posteriormente, como as de Almeida (2008), que abordou essa problemática nos contextos de Brasil, França e Portugal, e também de Zampieri, Javaroni e Silva (2015),

\footnotetext{
2 Embora essa edição do livro seja de 2010, a primeira foi realizada em 2001, e foi pouco alterada nas edições posteriores.
} 
que contemplou esses mesmos contextos, buscando compreender se o pouco uso destacado por Almeida (2008) permanecia, ou se o cenário já havia se tornado mais promissor.

Segundo eles, há expectativas positivas que poderão surtir efeitos a longo prazo, no que tange ao fomento a esse uso. Isso se dá, segundo os autores, pois os três países vem investindo significativamente na formação continuada de professores, pelo menos no que se refere a ações de formação docente, promovidas por cursos de extensão universitária ou por associações ou sociedades científicas. E mais, eles constataram que tais ações vêm buscando constituir cursos que tenham a colaboração como base, para que atendam às especificidades trazidas pelos professores, com as TD que apresentam sinergia com os objetivos de aprendizagem almejados por (ZAMPIERI; JAVARONI; SILVA, 2015).

Entretanto, somente o investimento na formação dos professores, seja ela inicial ou continuada, não será suficiente para promover o uso das tecnologias digitais, se os empecilhos de cunho burocrático, estrutural e político persistirem. Mais recentemente, pesquisas vinculadas ao projeto temático Mapeamento do uso das tecnologias de informação nas aulas de Matemática do Estado de São Paulo ${ }^{3}$, do qual os três autores desse artigo fazem parte, vinculado ao programa Observatório da Educação (OBEDUC), vem mostrando que tais empecilhos ainda se colocam frente a esse uso, e ainda são agravados por políticas públicas que não incentivam o uso da sala de informática, que por vezes, parecem dificultar esse uso devido à burocracia subjacente (JAVARONI; ZAMPIERI, 2015).

A esse projeto temático estão vinculadas pesquisas de iniciação científica, mestrado e doutorado, e conta ainda com a colaboração de professores universitários e professores de Matemática que atuam na Educação Básica. As seis regiões abarcadas por essas pesquisas estão situadas no entorno de cidades localizadas em pontos geográficos distintos dentro do Estado de São Paulo. As pesquisas vinculadas ao Mapeamento seguem uma abordagem qualitativa (JAVARONI; ZAMPIERI, 2015), pois se concentram em aspectos subjetivos referentes ao uso (ou ao não uso) das tecnologias pelos professores de Matemática que estão lotados nas Diretorias Regionais de Ensino situadas em cidades dessas seis regiões do Estado. Tais pesquisas se focalizam em três vertentes principais: investigações sobre as condições físicas dos laboratórios de informática das escolas da rede pública estaduais localizadas em tais regiões; investigações sobre o uso (ou não uso) das tecnologias pelos professores de Matemática lotados em tais escolas; investigações de cunho intervencionista, oferecendo cursos de extensão universitária a esses professores, com foco na articulação de atividades matemáticas com tecnologias, em particular o software dinâmico GeoGebra 4 .

Cabe destacar ainda que as pesquisas dentro da terceira vertente mencionada utilizam os seguintes procedimentos metodológicos, de modo geral: aplicação de atividades de caráter experimental, utilizando o software GeoGebra, aos professores de Matemática; diários de campo com as impressões dos pesquisadores e relatos de demais

\footnotetext{
${ }^{3}$ Projeto aprovado sob no 16429 no Edital 049/2012/CAPES/OBEDUC/INEP. Para dar maior fluidez ao texto, no referiremos a ele apenas como Mapeamento, ao longo do texto.

${ }^{4} \mathrm{https}: / /$ www.geogebra.org/ . Último acesso em 07.08.2017.
} 
colaboradores que contribuíram com o andamento dos dois cursos; videogravações de todos os encontros de cada curso.

Nesse artigo, especificamente, trazemos recortes referentes a dois professores que participaram dos cursos realizados em cidades dentro de duas regiões do Estado, sendo uma em Bauru, situada no noroeste do estado e a outra em Guaratinguetá, no Vale do Paraíba, que compõem os cenários das pesquisas de doutorado da primeira autora e do segundo autor, respectivamente. Em tais recortes, discutimos relatos desses professores, sobre aulas que ministraram com o GeoGebra, durante ou logo após a temporalidade de cada curso, e sobre os enfrentamentos que mobilizaram para cumprir os objetivos de aprendizagem que almejavam por meio das abordagens que propuseram.

A escolha por discorrer sobre essas situações e sobre esses professores se deu por termos indícios dessas mobilizações dentro de seus próprios contextos de trabalho, o que converge para o objetivo que propusemos nesse artigo. Isso não significa que não houve outros professores dos cursos que também o fizeram, mas para podermos nos aprofundar no tema ora proposto, optamos abordar apenas esses dois casos. Argumentamos que esses enfrentamentos vão ao encontro das atitudes de insubordinação criativa, conforme defendem D'Ambrosio e Lopes (2015). Para elas, tais atitudes se manifestam ao "assumir posturas que se contrapõem ao que está posto e determinado, seja pelo cotidiano profissional, seja por diretrizes legais. Estas seriam atitudes subversivas que visam a rupturas com o preestabelecido, de forma a criar novas dinâmicas de trabalho" (D'AMBROSIO; LOPES, 2015, p. 13).

Em Zampieri, Chinellato e Javaroni (2017) evidenciamos a ocorrência de atitudes de insubordinação criativa de professores e gestores, para que o laboratório de informática pudesse ser usado em aulas de Matemática. Tais atitudes foram evidenciadas para que o suporte técnico a computadores inoperantes fosse imediato, e não seguisse o protocolo de abertura de chamados ${ }^{5}$, exigido por instâncias superiores do Estado de São Paulo, que por sua vez, dificulta a concessão desse suporte, podendo demorar dias para que ele seja providenciado, segundo os próprios professores cursistas.

Assim, objetivamos nesse artigo expandir esse trabalho e aprofundar a discussão, destacando outras insubordinações criativas evidenciadas, em ambos os contextos. Temos o propósito ainda de discorrer acerca de possibilidades de desenvolvimento de atividades baseadas na abordagem experimental-com-tecnologia nas aulas de Matemática da Educação Básica (alunos de 11 a 17 anos).

Para aprofundarmos essa discussão, nos embasamos em dois referenciais teóricos, sendo o primeiro, o trabalho de Borba e Villarreal (2005), que versa a respeito da abordagem experimental-com-tecnologia. Já o segundo é sobre insubordinação criativa, e para elucidarmos esse termo e suas características, nos apoiamos em D'Ambrosio e Lopes (2015). No tópico seguinte apresentamos e dialogamos com esses dois referenciais.

\footnotetext{
${ }^{5}$ Mais especificamente, esses chamados chegam na Central de Serviços de tecnologia, da Fundação para o Desenvolvimento da Educação (FDE), do Estado de São Paulo, conforme constam em: http://www.fde.sp.gov.br/PagePublic/CentralServico.aspx?codigoMenu=52\&CentralServico=TI . Último acesso em 10.08.2017
} 


\section{Os cursos de formação continuada e suas características}

Como enunciado anteriormente, uma das frentes de atuação do projeto Mapeamento é propiciar cursos de formação continuada com professores de Matemática da rede pública paulista. Dos seis cursos que realizamos, no período de 2014 a 2016, dois deles serão aqui caracterizados pois neles verificamos indícios de insubordinação criativa, tanto dos proponentes do curso quanto dos cursistas. Um desses cursos foi realizado na cidade de Bauru, na região noroeste do estado de São Paulo, no segundo semestre de 2014 , entre os meses de agosto e novembro, totalizando uma carga horária de 40 horas, sendo 32 de forma presencial, no laboratório de informática da Diretoria de Ensino dessa região, e 8 horas a distância, pelo ambiente virtual de aprendizagem Moodle $^{6}$. $O$ objetivo desse curso foi o estudo do software GeoGebra, de forma articulada a conteúdos matemáticos vinculados ao currículo da disciplina de Matemática, do Estado de São Paulo. As atividades desenvolvidas tiveram um caráter investigativo, em sintonia com a abordagem experimental-com-tecnologia, conforme defendem Borba e Villarreal (2005).

Esse curso foi desenvolvido de forma flexível, a fim de abordar as demandas trazidas pelos professores, tanto sobre os conteúdos que queriam estudar, quanto os softwares que tinham preferência em se aprofundar, que por sua vez foi o GeoGebra. A equipe proponente responsável por ministrar o curso foi composta pela primeira e pela terceira autoras desse artigo, por duas alunas de iniciação científica (IC) da graduação em Matemática da UNESP de Bauru, e pela professora coordenadora de núcleo da disciplina de Matemática (PCNP), também colaboradora do projeto Mapeamento (JAVARONI; ZAMPIERI, 2015). Como trabalho final do curso, foi solicitado aos professores que elaborassem alguma atividade com o GeoGebra, e se possível, aplicassem com seus alunos e relatassem os acontecimentos da aula. No entanto, compreendemos que isso seria difícil de acontecer devido aos empecilhos já relatados para a utilização do laboratório de informática, então apenas a solicitação da criação da atividade já nos pareceu suficiente como trabalho final.

A fim de atender a demanda dos professores cursistas, no primeiro encontro, solicitamos que eles explicitassem suas expectativas com relação a nossa proposta, assim, ressaltaram a preferência por aprofundar os conhecimentos acerca do software GeoGebra, bem como elencaram os conteúdos que gostariam de abordar. Portanto, nos encontros seguintes, levávamos quatro atividades para que eles realizassem em pequenos grupos (no máximo quatro pessoas), e que avaliassem se as abordagens propostas contemplavam seus respectivos contextos ou não, e em caso negativo, que sugerissem adaptações àquelas que mais se adequassem aos objetivos que almejavam cumprir com seus alunos. E na sequência, fazíamos uma discussão envolvendo todos os professores, para que debatessem cada atividade, a fim de trocar ideias sobre as descobertas e sugestões de cada um, tanto acerca da abordagem, quanto das funcionalidades do GeoGebra.

\footnotetext{
${ }^{6}$ https://www.moodlelivre.com.br/tutoriais-e-dicas/974-o-que-e-moodle . Último acesso em 31.08.2017. O Moodle foi o ambiente de virtual de aprendizagem escolhido para desenvolvermos a carga horária a distância.
} 
O professor Rodrigo ${ }^{7}$, cujos relatos serão aqui debatidos, foi um dos participantes desse curso. Desde o início, ele acabou indo além das propostas das atividades que trazíamos, criando seu próprio material, e também descobrindo e compartilhando distintas funcionalidades do software GeoGebra com os demais colegas. Ele se formou em Matemática em uma universidade particular, em 2006, e também já trabalhou em uma empresa como gestor de compras. Na ocasião do curso, ele lecionava em uma escola pública que atende alunos do Ensino Fundamental II e de Ensino Médio, e está em funcionamento desde 1983. Esse professor foi um dos que conseguiu levar seus alunos ao laboratório de informática, durante o desenvolvimento do curso, e aplicou uma atividade uma atividade com o GeoGebra que abordou o Teorema de Pitágoras.

Já o curso realizado na região do Vale do Paraíba, mais especificamente na cidade de Guaratinguetá, no Estado de São Paulo, foi desenvolvido em 32 horas na modalidade presencial no primeiro semestre do ano de 2016, no laboratório de informática da respectiva Diretoria de Ensino, e contou com a participação de 34 docentes. A equipe proponente foi composta por um doutorando, segundo autor desse artigo, pela coordenadora do Mapeamento, terceira autora, por uma aluna de IC e pela PCNP da área de Matemática, vinculada àquela diretoria, e colaboradora do projeto. Os procedimentos metodológicos adotados para a produção dos dados dessa pesquisa, além dos já mencionados no primeiro tópico desse artigo, contaram com diário de campo no formato digital, gravado em áudio pelo pesquisador; por entrevista com os docentes; produção de vídeos educativos por meio da captura de tela pelo software Blueberry ${ }^{8}$, contendo as etapas de cada atividade, desenvolvidas pelo pesquisador já diretamente no software GeoGebra; e desenvolvimento de atividades articuladas aos Cadernos do Aluno e Professor (SÃO PAULO, 2014), material didático oficial do Estado de São Paulo.

Diferentemente do outro curso, esse não seguiu uma flexibilidade em termos de conteúdo, pois teve como objetivo a articulação desse material com o GeoGebra, uma vez que o interesse acerca desse entrelaçamento havia sido evidenciado nos cursos que antecederam esse, e, além disso, a PCNP que colaborou nesse curso fez um levantamento prévio, e constatou que os professores dessa região gostariam de uma dinâmica que possibilitasse essa articulação.

Assim, iniciamos o curso com atividades por nós elaboradas previamente, em colaboração com os demais pesquisadores do Mapeamento Contudo, já no primeiro encontro do curso, percebemos que os professores cursistas apresentavam dificuldades no desenvolvimento de tais atividades. Esse fato pode ter ocorrido já que muitos dos participantes não conheciam o GeoGebra. Assim, ao perceber o ocorrido, sugerimos a eles a possibilidade de elaborarmos vídeos, por meio da captura de tela do software Blueberry, contendo as etapas das construções necessárias para o desenvolvimento das atividades propostas no curso. Tal sugestão foi bem avaliada pelos professores cursistas e a partir de então iniciamos a confecção de vídeos educativos que foram utilizados em todos os encontros do curso.

Esse material era utilizado pelos participantes em conjunto com a elaboração e discussão das atividades propostas a cada encontro do curso. Esses vídeos não foram

\footnotetext{
${ }^{7}$ Os nomes dos professores serão alterados para preservar suas identidades e privacidades.

${ }^{8}$ https://www.flashbackrecorder.com/express/ . Último acesso em 18.08.2017.
} 
pensados a priori e foram emergentes no cenário de investigação, fazendo parte do design emergente de pesquisa, ou seja, consiste em "um planejamento flexível, que inclui os procedimentos e instrumentos de produção dos dados, bem como a análise dos mesmos [...] o pesquisador deve avançar à medida que a pesquisa se desenvolve, sem [...] passos rígidos estabelecidos a priori" (SOUTO, 2011, p.2).

É justamente essa ausência de passos rígidos que permitiu que o uso de vídeos, a partir do primeiro encontro, se tornasse um elemento fundamental do cenário de investigação, pois em todos os encontros eram realizados alguns vídeos com as atividades que seriam desenvolvidas, muitas delas por indicação dos próprios professores. Nas semanas seguintes do curso, a dinâmica se deu de modo que os docentes assistiam aos vídeos e realizavam as atividades, sempre colocando os seus pontos de vistas sobre o "melhor" modo de trabalhar esses conteúdos.

Essa dinâmica propiciou um grande diálogo entre os proponentes do curso e os cursistas. Um desses cursistas foi Warley, que leciona na rede pública de ensino há 12 anos e defende a ideia de que as TD podem contribuir para o ensino da Matemática facilitando a abordagem dos conceitos e contribuindo com a compreensão de abstrações por parte do aluno.

Depois de realizado o curso, o professor Warley se sentiu confiante em utilizar as TD em sua sala de aula para explorar o conceito de função exponencial. E para incentiválo nesse uso, o segundo autor desse artigo se colocou à disposição para auxiliá-lo nessa aula. Assim, foi marcado com antecedência uma data para o desenvolvimento dessa atividade no laboratório de informática da escola, atividade essa que será descrita a seguir.

Diante disso, no tópico seguinte, apresentamos e discutimos os relatos desses dois professores acerca do desenvolvimento de suas aulas com esse software, buscando detalhar os acontecimentos de tais aulas, destacando como superaram eventuais empecilhos.

\section{Atividades com o GeoGebra em sala de aula: dois exemplos}

Como já mencionado, o professor Rodrigo, do curso realizado na região noroeste do Estado, aplicou a atividade que elaborou como trabalho final do curso de formação, com seus alunos, no laboratório de informática da escola em que atuava na ocasião. Vale reforçar que esse professor foi bastante colaborativo ao longo do curso, ajudando os colegas e participando ativamente das discussões e sugerindo e criando atividades distintas daquelas que trabalhamos no curso. Em muitas dessas discussões, a maioria dos cursistas defendia a ideia de que antes de trabalhar as construções no software com seus alunos era necessário introduzir a eles, oralmente e por escrito, alguns conceitos prévios que alicerçavam as etapas das construções para abordar o conteúdo principal. Por exemplo, na atividade que desenvolvemos sobre Teorema de Tales, Teorema de Pitágoras, Gráficos de funções, entre outras, os cursistas argumentavam que seus alunos teriam dúvidas já nas etapas de construção, então teriam que ser revisados previamente com eles, conceitos como: representação de pontos no plano cartesiano, noções de perpendicularidade e paralelismo, intersecção, ponto médio, ângulos, dentre outros. 
Entretanto, Rodrigo sempre defendia o contrário, ou seja, alegava que a abordagem desses conceitos prévios, poderia ser realizada ao longo da própria construção envolvendo o conteúdo principal, conforme ele mesmo o fez em seu trabalho final.

Então no último encontro do curso, como parte do trabalho final, ele fez uma apresentação sobre a atividade que criou, abordando o conteúdo Teorema de Pitágoras, e sobre como foi a aplicação de tal atividade com seus alunos. Ao iniciar a apresentação, ele justificou a escolha desse conteúdo: "porque eles [os alunos] tem muitas dúvidas sobre triângulo retângulo, o que é semirreta, o que é ponto, e comecei a trabalhar isso com eles e acreditei que foi muito funcional" (professor Rodrigo). O roteiro de sua atividade pode ser visualizado na figura 1 , a seguir:

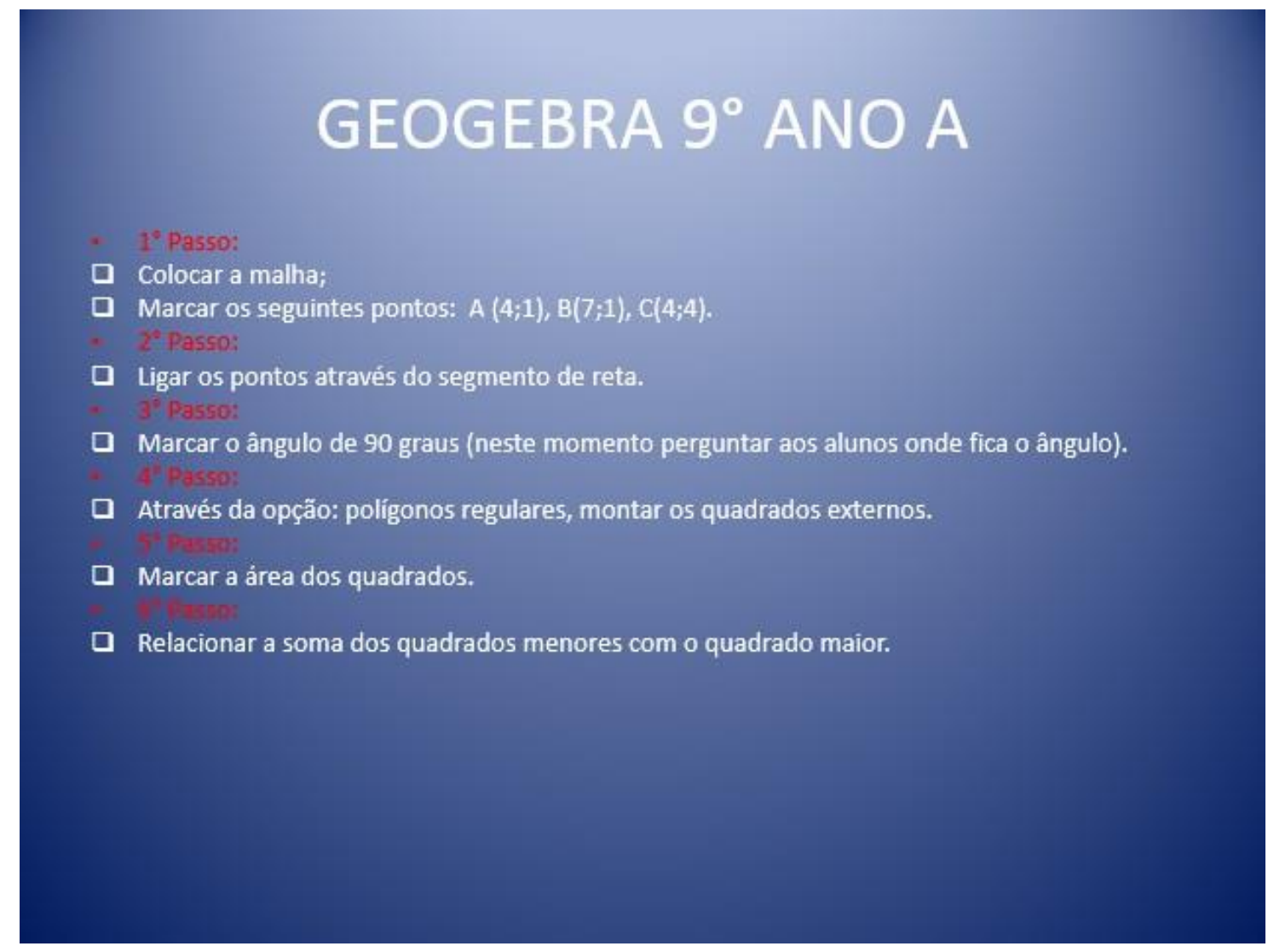

Figura 1 - Roteiro de atividade elaborada e aplicada em sala de aula por Rodrigo. Fonte: Os autores.

Em seguida, o professor começou a relatar como foi o trabalho com os alunos. Ele mencionou que aproveitou a etapa do $1^{\circ}$ passo da construção, que envolvia a representação dos pontos (representando os vértices das figuras) no plano cartesiano por meio da funcionalidade malha do GeoGebra, conforme solicitado na Figura 1, e questionou aos alunos sobre como deveriam representar os pontos no plano. "Aí eles abriram o GeoGebra né, e colocaram a malha, marcaram os segmentos, os pontos, o ponto $(4,1)$, aí eu perguntava para eles, aquele 4 , em qual eixo que é? eixo $x$ ou eixo y?" (Professor Rodrigo). E esses questionamentos, segundo ele, proporcionaram aos alunos a oportunidade de já tirarem suas dúvidas sobre esses conceitos prévios que eram necessários para efetuar a construção. Ou seja, assim como ele defendia ao longo dos encontros do curso, ele realizou a revisão dos conceitos básicos para a construção 
utilizando o próprio software, reforçando seu argumento para os demais cursistas que refutavam essa possiblidade.

Rodrigo destacou ainda que, na verdade, foram necessárias três aulas para o desenvolvimento completo dessa atividade, para que os alunos pudessem ter um amplo entendimento do conteúdo principal, que era o Teorema de Pitágoras, e sobre a conceitualização necessária para a abordagem desse conteúdo. Ele relatou que o projetor multimídia que estava utilizando no laboratório, para que os alunos acompanhassem cada etapa junto com ele, apresentava a imagem meio trêmula e um pouco desfocada, então em suas próprias palavras, ele precisou "ficar nivelando" o equipamento. O professor também teve ajuda de um técnico que trabalhava e estudava na escola, para conseguir utilizar esse projetor.

Rodrigo disse que, junto com o técnico, tiveram que fazer esse conserto de improviso, popularmente conhecido como "gambiarra", como ele próprio destacou, para poder projetar o roteiro da atividade e seguir com a dinâmica de aula que havia planejado. Ele chegou a comparar essa situação com uma cena do filme Homem de ferro 2, em que o personagem que dá título ao filme utiliza o escudo de outro personagem, o Capitão América, para fazer uma "gambiarra" e terminar a construção de uma máquina que estava projetando. Bem-humorado, Rodrigo aconselhou aos demais professores: "então tudo isso vocês vão estar enfrentando em sala de aula, são os ajustes [...]". Ele ainda alertou sobre a necessidade de ir antes ao laboratório de informática para deixar tudo pronto para o desenvolvimento da aula.

Destacamos a atitude de insubordinação criativa (D'AMBROSIO; LOPES, 2015) do professor Rodrigo aqui, pois ele não deixou que a burocracia decorrente das normas do laboratório inviabilizasse a aula que havia planejado. Ou seja, se ele fosse seguir à risca o protocolo, deveria solicitar a abertura de um chamado, conforme já mencionamos anteriormente, o qual seria analisado pela Fundação de Desenvolvimento da Educação, em São Paulo, e a partir disso teriam que aguardar a aprovação e depois o conserto do equipamento, que poderia demorar dias, e essas aulas sequer teriam ocorrido.

Dando sequência a sua apresentação, o professor enfatizou que os alunos nunca haviam tido contato com o GeoGebra, contudo, argumentou que não houve dificuldade alguma, pois todos permaneceram atentos fazendo a atividade, seguindo os passos que eram mostrados no projetor. Rodrigo ressaltou, inclusive, que um de seus alunos se antecipou e finalizou antes a atividade, sem nunca ter usado o software. Relatando os acontecimentos da aula, ele disse: "Ah, já sei mais ou menos o que tem que fazer [simulando a fala do aluno]". Assim, segundo o professor, esse aluno e mais dois colegas que formaram um grupo, se anteciparam e finalizaram a atividade. Rodrigo concluiu: "os três detonaram, eles fizeram na frente o negócio, porque eles já sabiam o Teorema de Pitágoras, a comparação entre os quadrados [...]". Um aspecto importante ressaltado por ele foi a colaboração entre os alunos no desenvolvimento da atividade: "Outra coisa que teve, muita parceria entre eles, um levantando do micro e indo ajudar o outro". Depois ele ressaltou novamente a necessidade de ir antes ao laboratório e já deixar tudo organizado para a aula. 
Assim, ao aplicar com os alunos uma atividade em sintonia com a abordagem experimental-com-tecnologia, de Borba e Villarreal (2005), o professor conseguiu abordar, além do conteúdo principal, os conceitos envolvidos na construção, como a representação de pontos no plano cartesiano, tirando as dúvidas de seus alunos por meio de questionamentos. Além disso, propiciou que os alunos se envolvessem com o desenvolvimento da atividade, deixando que suas ações, tentativas e erros fossem condicionados pelo GeoGebra, contribuindo também para que eles ficassem ao centro de seus próprios processos de aprendizagem (D'AMBROSIO; LOPES, 2015).

Ele mencionou que fez o download desse software na internet. Entretanto, a PCNP de Matemática, e uma das alunas de IC, que faziam parte da equipe proponente do curso, advertiram a ele e aos demais professores, que nos computadores dos laboratórios regidos pelo programa Acessa Escola ${ }^{9}$, esse software e os demais disponibilizados pelo programa se encontram em uma pasta chamada "ferramentas educativas". Contudo, o professor Rodrigo alegou que precisava de uma versão mais atual do software, do que a versão daquele que estava disponível nos computadores do laboratório. A PCNP alertou que para atualizar o software, ele precisaria ter solicitado a abertura de chamado, para que, posteriormente a atualização pudesse ser feita. Nesse momento, alguns professores e nós, da equipe proponente do curso, nos indignamos com tamanha burocracia, e então a coordenadora do projeto Mapeamento, que é terceira autora desse artigo, e o professor Rodrigo, argumentaram sobre a urgência de ter uma pessoa mais próxima para prestar esse tipo de suporte.

Ele ainda reiterou: "Eu não vou deixar de dar aula por causa da burocracia". E

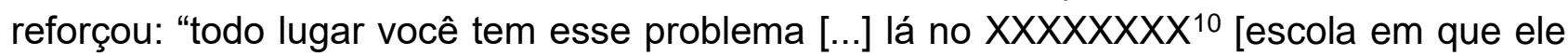
atuava], a gente tem assim muita liberdade para o trabalho, se acontecer alguma coisa, você vai ter quem te ajude na briga". Destacamos aqui dois aspectos: a burocracia que engessa o trabalho do professor, que vai ao encontro do que já relatavam Borba e Penteado (2010), e que converge para as falas dos professores, atualmente, quando destacam empecilhos para usar as TD em sala de aula, e que também vão ao encontro dos resultados das pesquisas vinculadas ao projeto Mapeamento, destacados inicialmente (CHINELLATO, 2014; OLIVEIRA, 2014; JAVARONI; ZAMPIERI, 2015). O segundo aspecto que destacamos é a importância do apoio da gestão escolar, que por meio de uma postura colaborativa, garantem o respaldo para as atitudes de insubordinação criativa (D'AMBROSIO; LOPES, 2015) dos professores, fazendo com que esses consigam exercer sua profissão dignamente, priorizando a aprendizagem de seus alunos.

Continuando sua apresentação, Rodrigo mostrou no projetor, a atividade realizada por um aluno, destacando que ele mesmo havia feito a alteração das cores, entre outras alterações na construção. Observamos que, mesmo a atividade sendo sobre Teorema de Pitágoras, e com algumas similaridades em relação ao roteiro que já havíamos trabalhado ao longo do curso, ele fez algumas alterações no roteiro, como a construção do triângulo

\footnotetext{
${ }^{9}$ Esse programa é do governo estadual do Estado de São Paulo, está vigente desde 2008, e tem como propósito fomentar a inclusão digital dentro da comunidade escolar. Os computadores contam com pacotes educacionais, como softwares matemáticos, sendo o GeoGebra um deles. Mais informações podem ser obtidas em http://www.educacao.sp.gov.br/acessa-escola . Último acesso em 10.08.2017.

$10 \mathrm{O}$ nome da escola vai ser mantido em sigilo para preservar a identidade do professor.
} 
por pontos e não por retas perpendiculares, conforme abordagem que havíamos proposto em alguns encontros anteriores. Esse fato, por um lado, deixa a construção um pouco mais estática, pois dependendo de como o triângulo for movimentado, ele deixa de ser triângulo retângulo por não ter o ângulo reto garantido pela construção utilizando-se a funcionalidade de perpendicularidade do software.

Entretanto, ao mover por um único ponto, que não seja o que corresponde ao ângulo reto, a abordagem proposta por ele possibilitou uma mobilidade da figura, e além disso, propiciou trabalhar com outros conceitos que ele tinha necessidade de reforçar com seus alunos, como a semirreta e a representação de pontos no plano cartesiano. Desse modo, o professor adaptou a atividade visando atender ao seu contexto específico, conseguindo aproveitar as potencialidades do software, para abordar de forma dinâmica distintos conceitos ao mesmo tempo, em sinergia com a abordagem experimental-comtecnologia, de Borba e Villarreal (2005).

Depois de encerrada sua apresentação, foram feitas algumas questões para Rodrigo, sendo uma delas sobre a quantidade de alunos para o número de computadores, e a outra, sobre a dinâmica de aula que ele adotou. Ele disse que os alunos se organizaram em grupos, de preferência em trios, e que eram mais ou menos 40 alunos. "Para eles foi interessante sentar em dupla, pois um corria ajudar o outro [...] e a gente salvou [as atividades], dei nota sobre isso para eles, lógico que eu dei 10 para eles, pela participação" (professor Rodrigo). Uma das alunas de IC perguntou se ele entregou o roteiro impresso das atividades para os alunos, e ele respondeu:

Ao invés de entregar o roteiro, para não gastar papel, eu coloquei o roteiro no projetor. Eu abria o GeoGebra [e começou a simular sua aula na apresentação] daí eu abria lá o roteiro para eles, estava no word, então estava esse roteiro lá, bem maior. Então eu abria o GeoGebra, então o que que eu ia fazendo. Então estava esse roteiro, então pessoal [simulando como se fosse para os alunos], primeiro ponto, aí eu orientei eles a abrirem a malha, bem devagar...aí vamos para o próximo passo, marcar o ponto $(4,1)$, quem que é o quatro para vocês [simulando conversa com os alunos], onde eu vou marcar esse ponto (Professor Rodrigo).

A coordenadora do Mapeamento perguntou a ele se foi a primeira vez que levou os alunos ao laboratório, e ele respondeu que para trabalhar com o GeoGebra sim, mas ressaltou que o laboratório é bastante utilizado nessa escola, de maneira geral. "Lá a gente usa bastante o laboratório [...], mas o GeoGebra foi a primeira vez". Isso reforça que quando os professores já estão predispostos a usar as tecnologias digitais, esse fator associado a outros externos, como a própria participação em um curso que os deixa à vontade para escolher os conteúdos e o software com o qual querem trabalhar, e que proporciona um ambiente propício para refletir acerca da sua prática didática, que oportuniza troca de experiências com seus pares, incentivando o trabalho colaborativo, bem como o apoio da equipe gestora e técnica da escola (ZAMPIERI; JAVARONI; SILVA, 2016), possibilitam impactos em sala de aula, conforme o desenvolvimento dessa atividade relatada por Rodrigo. Por fim, ele novamente incentivou os colegas a fazerem o mesmo: 
[...] eu já sei o que o laboratório vai causar ali na frente de gargalo [reforçando a necessidade de ir antes, para evitar problemas técnicos durante a aula], cabe a mim estudar o que eu vou passar, eu já sei os gargalos. Vocês vão ter problemas [alertando os demais professores], às vezes o micro não funciona, o datashow, você tem que fazer aquelas gambiarras (Professor Rodrigo).

Esses relatos do professor Rodrigo mostram que há necessidade de um tempo maior de planejamento da aula, para incorporar as tecnologias digitais a ela de modo a minimizar possíveis ocorrências de problemas técnicos, em particular se esse uso ocorrer no laboratório de informática. Entretanto, reiterou aos demais colegas que esse esforço vale a pena, uma vez que o resultado em sala de aula, no que tange ao desempenho dos alunos, pode ser além do esperado, e ainda pode contribuir para que os alunos adquiram uma postura colaborativa, conforme enfatizado por ele.

Já no curso realizado em Guaratinguetá, também foram evidenciadas atitudes de insubordinação criativa, porém, motivadas por outras circunstâncias. O professor Warley, participante desse curso de formação continuada, solicitou ao pesquisador responsável pela condução do curso, o segundo autor desse trabalho, auxílio para utilizar o GeoGebra em uma de suas aulas que ministraria no $1^{\circ}$ ano do Ensino Médio, para explorar o conteúdo referente à função exponencial. Dessa forma, juntamente com esse professor cursista, foi agendada uma data para essa aula. Na semana em que antecedeu essa aula, mensagens foram trocadas pelos aplicativos WhatsApp e Facebook, com a finalidade de elaborar o planejamento da aula, levando em consideração as competências e habilidades a serem trabalhadas pelo professor com seus alunos, bem como abordando $o$ conteúdo com atividades investigativas na perspectiva da abordagem experimental-comtecnologia (BORBA; VILARREAL, 2005).

Essas trocas de mensagens aconteceram até a véspera da ocorrência da aula. Verificamos então com o professor Warley acerca da pertinência da produção de um vídeo sobre as construções que ela trabalharia com os alunos nessas atividades da aula. Ele julgou interessante essa proposta e, assim fizemos um vídeo educativo mostrando as etapas de construção sobre uma atividade de função exponencial no GeoGebra. A produção desse vídeo educativo seguiu os moldes dos que foram realizados durante todo o curso, ou seja, foi produzido a partir da captura de tela do software Blueberry, com foco nas etapas da construção dos gráficos no software GeoGebra. A partir desse vídeo, o professor realizou algumas adaptações na atividade, utilizando as mesmas funções exponenciais representadas no material didático. $O$ seu propósito era desenvolver as construções junto com os alunos, projetando a tela do GeoGebra na sala de informática, por meio do projetor multimídia.

No dia agendado para a ocorrência da aula o pesquisador foi até a escola e auxiliou o professor Warley em 4 aulas, sendo duas em uma turma do primeiro ano e outras duas em outra turma do primeiro ano. Ao levar os alunos da primeira turma ao laboratório de informática, um primeiro imprevisto acontece, já que o professor e os alunos não sabiam como fazer o login nos computadores. Após certo tempo (20 minutos), com o auxílio da secretária da escola, descobrimos que era necessário ligar o computador central do laboratório para depois ligar os demais. Esse fato reforça a observação que 0 professor Rodrigo, professor cursista do outro curso de formação, havia comentado em 
sua fala, que no planejamento de uma aula realizada no laboratório, deve-se visitar previamente as instalações do laboratório e verificar as condições de uso. Infelizmente não nos atentamos a esse fato naquela ocasião.

Por outro lado, ficamos aqui nos indagando: se houve um agendamento prévio e se há responsáveis pelo laboratório, a sala já não deveria estar preparada antes por tais responsáveis? Ou, pelo menos os computadores já não poderiam estar devidamente ligados para facilitar o trabalho do professor que agendou a sala, uma vez que ele já "perde" tempo com a locomoção dos alunos até esse local?

Mesmo que as respostas a essas indagações fossem negativas (o que não deveria, no nosso modo de ver), pelas próprias normas de funcionamento do Acessa Escola, há os responsáveis pelo laboratório dentro de cada escola, que já poderiam ter dado uma orientação antecipada ao professor, assim que ele realizou o agendamento da sala. Como isso não ocorreu, por mais que a sala já estivesse reservada para a utilização do laboratório, o percalço decorrente dessa falha de comunicação atrasou o desenvolvimento da aula. O segundo problema que surgiu estava atrelado ao notebook do laboratório que estava presente na escola, o qual seria utilizado para 0 desenvolvimento da atividade no projetor. Entretanto, esse notebook não reconheceu o projetor multimídia disponível naquele ambiente de ensino.

Para solucionar isso, o doutorando emprestou seu notebook a ele para o desenvolvimento das atividades. Tal situação nos remete a relembrar o cenário descrito em Borba e Penteado (2010), que já atentavam para esses problemas de equipamentos e infraestrutura desde 2001. Os resultados mais recentes do projeto Mapeamento mostram que tais problemas ainda persistem, conforme já mencionado no primeiro tópico desse artigo, que vão ao encontro desse empecilho que aconteceu com Warley. Entretanto, fazendo uma análise mais aprofundada dessa situação, pode-se observar que tais problemas técnicos não foram a causa por si só. Na verdade, foram consequência da falta de uma parceria colaborativa entre os responsáveis pelo laboratório com o professor, por não se certificarem do funcionamento dos equipamentos previamente, mesmo as aulas tendo sido agendadas com antecedência.

Esses responsáveis, conforme consta na própria página do Acessa Escola (SÃO PAULO, 2016), podem ser alguém da equipe gestora, da equipe administrativa da escola, de professores readaptados, ou de algum professor, desde que seja acordado com a direção da escola previamente. Uma das funções desses responsáveis deveria ser, no mínimo, conhecer o mecanismo de funcionamento do laboratório, em especial sobre os computadores do laboratório, e consequentemente orientar os professores que agendaram o uso da sala. Entretanto, essas informações básicas não foram repassadas ao professor.

No entanto, se ele não teve esse suporte por parte dos responsáveis pelo laboratório, o mesmo não aconteceu por parte do doutorando, que por meio do empréstimo de seu notebook, possibilitou que esse percalço fosse sanado ainda em tempo de desenvolver a dinâmica de aula que Warley havia planejado. Esse contratempo mencionado não foi de cunho burocrático, e a solução para ele também não desconsiderou a nenhuma norma proveniente de instâncias superiores. Contudo, 
defendemos que tanto Warley quanto o doutorando tiveram atitudes de insubordinação criativa porque mesmo diante de um atraso de mais de 20 minutos, eles resistiram a essas adversidades, encontraram uma solução paliativa, ministraram a aula, e conseguiram desenvolver e alcançar o que haviam planejado, segundo o próprio professor Warley destacou.

Ademais, vale destacar ainda outra atitude de insubordinação criativa (D'AMBROSIO; LOPES, 2015) do doutorando, uma vez que, mesmo não obtendo aprovação para filmagens e audiogravações das aulas, se predispôs a ajudar o professor mesmo se abdicando de procedimentos metodológicos mais rígidos para a produção de seus dados, que Ihe trariam mais elementos para aprofundar sua análise posteriormente. Os relatos aqui mencionados sobre esses momentos prévios e também os que ocorreram durante as aulas são frutos do diário de campo do pesquisador, que ele realizou por meio de áudio, na tentativa de buscar relatar todos os detalhes das aulas e da conversa posterior que teve com o professor.

Voltando a descrição e análise do ocorrido na aula, após esses contratempos, o professor Warley a iniciou explicando brevemente o software aos alunos, e na sequência, começou a realizar as atividades junto com eles, retomando os conteúdos que estavam sendo desenvolvidos em sala de aula. Enquanto o professor Warley dava andamento na atividade, o doutorando ajudou os alunos que apresentavam dúvidas relacionadas com o GeoGebra ou com as construções matemáticas que estavam propostas para a exploração e investigação sobre a função exponencial.

Warley começou a aula mostrando que o conteúdo estava presente no Caderno do Aluno (SÃO PAULO, 2014), e começou a construção dos gráficos presentes nesse material. Primeiramente construiu com os alunos a tabela " $x$ " e " $y$ " da função " $y=2 x$ ", mostrando que era possível realizar no software a mesma tabela que fora construída no caderno deles. Em seguida, foram traçados, por meio dos pares ordenados $(\mathrm{x}, \mathrm{y})$, pontos no GeoGebra que indicavam a curva de um função exponencial crescente.

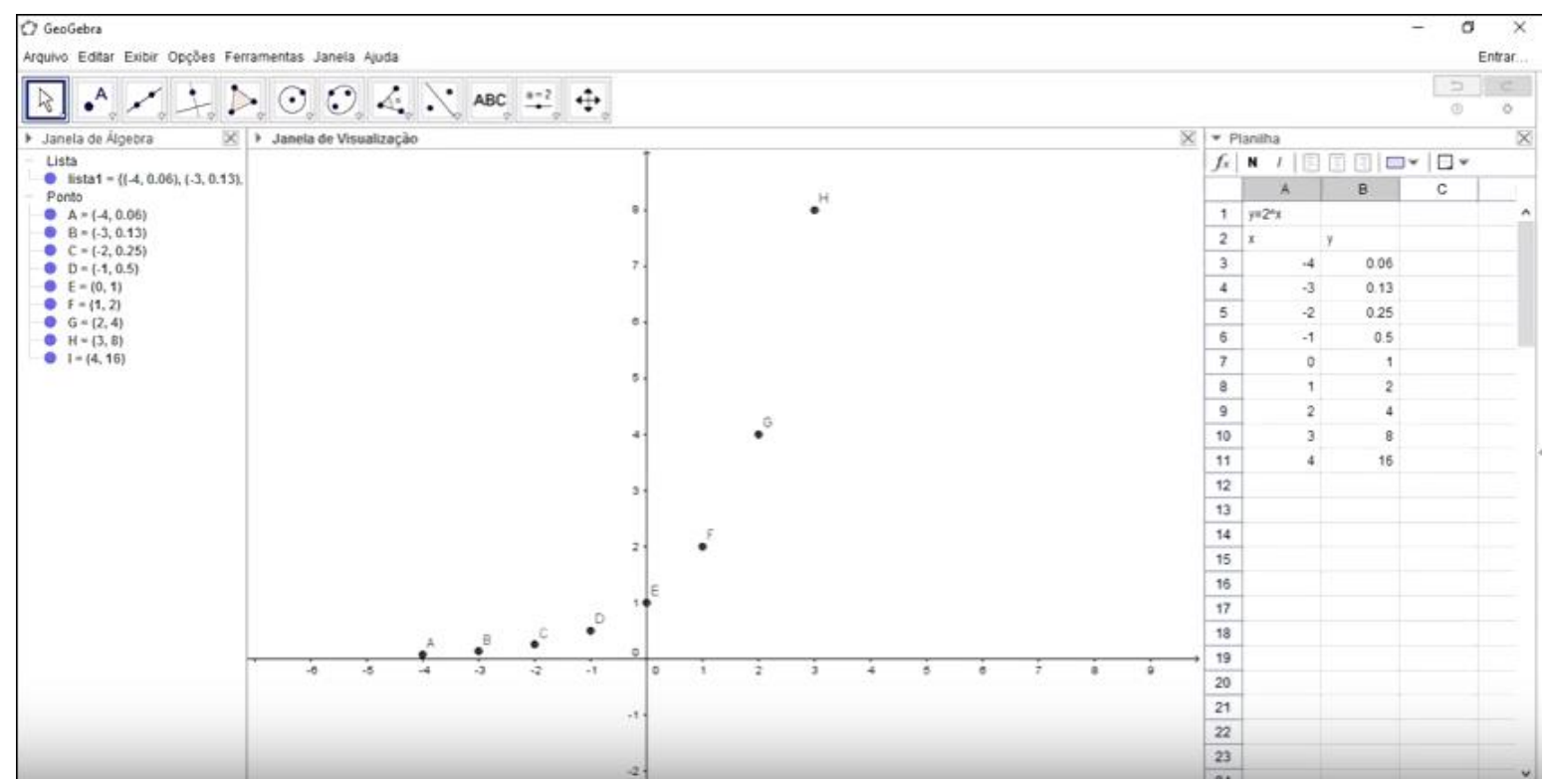

Figura 2 - Tela do GeoGebra com a construção da atividade proposta.

Fonte: Os autores. 
Durante o desenvolvimento da atividade, os alunos participaram fazendo questionamentos ao professor, condicionados pelo feedback do software, em sinergia com as características da abordagem experimental-com-tecnologia de Borba e Villarreal (2005). Em seguida, o professor pediu para os alunos realizarem a construção de outra função exponencial sendo a lei de formação da função " $y=1 / 2 x$ ". Com essas duas plotagens, o professor relembrou com os alunos as características de funções exponenciais crescentes e decrescentes. A mesma atividade foi desenvolvida com a segunda turma, durante a terceira e quarta aula respectivamente, não ocorrendo nenhum dos dois contratempos ocorridos nas duas primeiras aulas. Entretanto, é importante ressaltar que, mesmo com os percalços, o desempenho dos alunos nas duas primeiras aulas correspondeu às expectativas do professor, conforme ele mesmo nos relatou.

Ao final das aulas daquela manhã, conversamos com o professor Warley para refletirmos acerca da experiência que acabávamos de vivenciar, ou seja, para sabermos do professor, em sua visão, como ele avaliaria a experiência do uso das TD em sua aula de Matemática. O primeiro comentário do professor cursista foi sobre a importância de ter alguém junto com ele, auxiliando uma aula que envolvesse tecnologia. Ele continuou nos dizendo que observou a participação de alunos que geralmente nunca prestavam atenção na aula. Segundo o professor Warley, a TD proporcionou essa mobilização, pois faz parte da realidade dos alunos. E mais uma vez o professor reforçou ter ficado muito surpreso com a reação de alguns alunos.

Sobre os problemas técnicos enfrentados para o desenvolvimento da aula, Warley foi bem enfático dizendo que infelizmente isso é recorrente na escola pública, mas que se arriscar vale a pena. Mesmo não tendo sido fácil, por causa das burocracias e da falta de informação sobre como usar esses equipamentos, Warley destacou que estava satisfeito com o que evidenciou nessas aulas, principalmente por ter conseguido desenvolver com os alunos as atividades, e de ter motivado alunos que normalmente não demonstram interesse em suas aulas.

As adaptações das atividades do Caderno do Professor de Matemática para abordagens que favorecessem a experimentação, em consonância com a abordagem experimental-com-tecnologia (BORBA; VILLARREAL, 2005), foram realizadas com sucesso por Warley, sempre levando em conta, levando em conta o preparo das aulas, bem como o conhecimento prévio de seus alunos. As características da insubordinação criativa foram evidenciadas durante essa aula, na qual o professor utilizou o software GeoGebra aproveitando de sua plasticidade para favorecer a experimentação, para ensinar e enfatizar os conteúdos de função exponencial, indo além do que estabelece o material didático paulista (SÃO PAULO, 2014), colocando o aluno no centro de seu processo de aprendizagem, de acordo com D'Ambrósio e Lopes (2015), contando com o apoio do doutorando.

Diante de tudo o que foi exposto, reiteramos que enquanto as políticas públicas e as burocracias advindas delas não contribuírem para fomentar o uso das tecnologias digitais em sala de aula, só será possível que os professores desenvolvam atividades dessa natureza com seus alunos por meio do aprofundamento de seus conhecimentos acerca de tal abordagem, junto às atitudes de insubordinação criativa deles, de gestores, de outros profissionais que atuam no ambiente escolar, e de pesquisadores que se 
dispuserem a ajuda-los, mesmo que isso custe a abdicação de procedimentos metodológicos mais rígidos.

Mesmo tendo que enfrentar alguns empecilhos técnicos para ministrarem suas aulas, os dois professores relataram algo em comum: que o esforço valeu a pena, pois perceberam a motivação dos alunos, inclusive daqueles que nem sempre participam, como foi o caso relatado por Warley. Assim, em consonância com D'Ambrosio e Lopes (2015, p. 15), acreditamos que "é essencial utilizar nossos saberes de forma a proteger a integridade de nossos estudantes e de nossos espaços formativos, neutralizando os efeitos desumanizadores da autoridade burocrática" (D'AMBROSIO; LOPES, 2015, p. 15).

Por fim, buscamos destacar o trabalho de dois professores de Matemática, acerca de suas aulas com o software GeoGebra, bem como os seus enfrentamentos, e suas perspectivas em relação ao trabalho realizado por seus alunos. Ainda, buscamos destacar a importância do apoio da gestão escolar, bem como de pesquisadores, no caso de Warley, para que os professores atuem de forma autônoma e criativa, e para o respaldo diante de aspectos burocráticos, de modo que estes não os impeçam de promover enfoques pedagógicos como esses relatados. A seguir, tecemos algumas reflexões que emergiram a partir da escrita desse artigo.

\section{Reflexões emergentes para além dessas aulas}

Se a gente quer o novo, se a gente quer mudar, tem que ter criatividade, tem que dar a oportunidade para o novo [...]"11. Essa foi uma fala que consideramos chave, dita pelo Prof. Dr. Ubiratan D'Ambrósio, que vai ao encontro de ideias debatidas por D’Ambrósio e Lopes (2015), que foi pronunciada em sua palestra impregnada de emoção, na I Conferência Internacional de Insubordinação Criativa (ICOCIME), que aconteceu no início de agosto, em São Paulo. Essa frase nos chamou a atenção, pois harmoniza com o que buscamos salientar nesse artigo, que foram as atitudes de insubordinação criativa que possibilitaram aulas de Matemática em que as tecnologias foram utilizadas de forma a favorecer a aprendizagem dos alunos, por meio da experimentação, da simulação, da plasticidade.

Entretanto, em meio aos relatos dos professores que aqui destacamos, percebemos o quanto a burocracia e a falta de comunicação/colaboração podem afetar o trabalho docente, e estamos nos referindo apenas ao uso dos laboratórios de informática das escolas estaduais paulistas. Se pararmos para analisar a situação de uma forma mais ampla, tomando ainda o contexto desse estado, observamos um contínuo processo de normatização das escolas, estando o Sistema de Avaliação de Rendimento Escolar do Estado de São Paulo (SARESP) no centro desse processo. Dizemos isso tomando como referência os professores cursistas, com os quais convivemos ao longo do desenvolvimento de cada curso. Ou seja, obter boa pontuação nessa avaliação se tornou primordial nas escolas, o que, por sua vez, parece direcionar o que deve ser abordado em

\footnotetext{
${ }_{11}$ Palestra sobre "Insubordinação criativa em pesquisa e em educação", proferida pelo Prof. Dr. Ubiratan D’Ambrosio, no I ICOCIME, na UNICID em São Paulo, no dia 01/08/2017. Disponível em: https://www.youtube.com/watch?v=-FK_IsN4OVU\&index=1\&list=PLbJ66hjyuM72G1LixW Iry-hhra8Ao6fjF . Último acesso em 31.08.2017.
} 
sala de aula, o que, por sua vez, direciona a periodicidade em que cada conteúdo deve ser abordado, que resulta em uma limitação para a atuação do professor.

Essa limitação se expressa na própria "recomendação" de uso do material didático, que se refere ao caderno do professor e o caderno do aluno (2014). Segundo Crecci e Fiorentini (2014), há uma obrigatoriedade implícita desse uso, que pode ser observada na rotina de trabalho do professor. De fato, nos cursos ofertados pelo projeto Mapeamento, não somente nesses que estão aqui sendo abordados, mas também nos demais, percebemos nos relatos dos professores a necessidade que eles sentem em ter que seguir esse material, que se refletiu até no planejamento de alguns cursos, como esse de Guaratinguetá, em que as atividades realizadas foram baseadas nesse material. No curso de Bauru, isso também se refletiu, mas não em um primeiro momento. Como este foi o primeiro curso, as atividades foram baseadas nos conteúdos que os professores elencaram, mas o planejamento das atividades não teve como base esse material. Entretanto, as adaptações das atividades, que eram sugeridas pelos professores, na maioria das vezes, eram pensadas visando entrelaçar com atividades presentes no material.

Então tudo isso faz parte desse nítido processo de normatização que estamos vivenciando atualmente. Conforme argumentou o professor Ubiratan D'Ambrosio em sua palestra, tomando como referência o matemático Seymour Papert, junto com a modernidade caminham os regulamentos. Cada dia que passa, há novos regulamentos para seguir, e a perda da própria autonomia em sala de aula caminha também nesse mesmo sentido, no nosso modo de ver. Então, diante desse panorama, levantamos a seguinte indagação, tendo em mente a frase chave que iniciamos esse tópico: quem quer inovar dentro dessa realidade? Alguém quer mudar esse cenário?

Tomando como base as políticas públicas que regem o cenário educacional paulista, as respostas nos parecem negativas, tendo a referência da própria discussão que aqui estamos fazendo sobre o processo de normatização e tudo o que decorre dele. Outro fator que nos leva a crer nisso se refere à restrição do cargo de professores auxiliares, conforme Portaria CGRH-3, de 9 de abril de 2015 (SÃO PAULO, 2015). Felizmente, dentro desses contextos em que mencionamos, observamos que singularidades podem fazer a diferença.

Reconhecemos também que o material didático ofertado pelo estado apresenta potencial para o desenvolvimento de abordagens que possibilitam o entrelaçamento com o uso das TD, como pudemos observar no decorrer dos cursos desenvolvidos pelo projeto. Entretanto, o que nos incomoda é a questão da "recomendação" que ele seja seguido na íntegra, e principalmente, dentro de um limite determinado de tempo, porque pode inibir o professor de utilizar outros materiais, e até mesmo de articular tais atividades com as tecnologias, por receio de extrapolar o tempo pré-determinado para abordar cada conteúdo.

Agora, voltando às duas questões, e pensando nos professores que atuam na Educação Básica, e que participaram desses dois cursos, especificamente, respondemos: muitos querem mudar, muitos querem inovar esse cenário, pelo menos no que tange ao uso das TD em sala de aula. Por meio dos relatos desses dois professores, observamos que tal inovação é possível, desde que eles se sintam motivados a fazer esse uso, e desde que haja apoio, seja por parte da gestão escolar, seja por parte de outros membros 
da escola. Em sinergia com a frase chave destacada no início do tópico, os professores ousaram, foram criativos, e mudaram o cenário de suas aulas, mesmo que pontualmente, dentro daquelas ocasiões. Paralelamente, os gestores de suas escolas oportunizaram isso, na medida em que apoiaram essas iniciativas singulares, contribuindo diretamente para que essas aulas acontecessem.

Sabemos que não é a situação ideal, pois diante do processo de normatização, ser criativo é seguir na contramão. Entretanto, há professores dispostos a seguir na contramão, como vimos aqui, se esse for o sentido que prioriza a aprendizagem. Ademais, há gestores dispostos a não seguir à risca certos regulamentos, se estes inviabilizam a ação docente. Por fim, enquanto pesquisadores, ao longo do desenvolvimento de tais cursos, aprendemos muito sobre essa realidade escolar, e principalmente, sobre essas atitudes de insubordinação criativa de professores e gestores. Assim, por acreditarmos que as particularidades podem fazer a diferença no todo, buscamos nesse artigo destacar essas atitudes, com a esperança de que possam ecoar no meio acadêmico, ecoar no meio escolar, e que possam fomentar a ocorrência de novas particularidades.

\section{Agradecimentos}

O trabalho apresentado foi realizado com o apoio da CAPES, entidade do Governo Brasileiro voltado para a formação de recursos humanos.

\section{Referências}

ALMEIDA, M. E. B. Tecnologias na Educação: dos caminhos trilhados aos atuais desafios. Bolema, Rio Claro (SP), ano 21, n. 29, p. 99-129, 2008.

BAIRRAL, M. A. Materiais curriculares educativos online como uma estratégia ao desenvolvimento profissional em matemática. Zetetiké, v. 24, n. 45, p. 75-92, 2016.

BORBA, M. C.; PENTEADO, M. G. Informática e Educação Matemática. 4ª . ed., Belo Horizonte: Autêntica, 2010.

BORBA, M. C.; VILLARREAL, M. Humans-With-Media and the Reorganization of Mathematical Thinking: information and communication technologies, modeling, experimentation and visualization. New York: Springer. v. 39. (2005).

CHINELLATO, T. G. O uso do computador em escolas públicas estaduais da cidade de Limeira/SP. 2014. Dissertação de Mestrado (Educação Matemática) - Universidade Estadual Paulista, Instituto de Geociências e Ciências Exatas, Rio Claro, 2014.

CRECCI, V. M.; FIORENTINI, D. Gestão do Currículo de Matemática sob Diferentes Profissionalidades. Bolema, Rio Claro (SP), v. 28, n. 49, p. 601-620, 2014.

D'AMBROSIO, B. S.; LOPES, C. E. Insubordinação Criativa: um convite à reinvenção do educador matemático. Bolema, Rio Claro (SP), v. 29, n. 51, p. 1-17, 2015.

D'AMBROSIO, U. Educação Matemática: da teoria à prática. 16 ${ }^{\underline{a}}$ ed., Campinas: Papirus, 2008. 
FERNANDES, A. C. P.; VISEU, F. A. V. Os ambientes de geometria dinâmica no desenvolvimento da capacidade de argumentação de alunos do $9^{\circ}$ ano na aprendizagem de Geometria. Em: Atas ProfMat 2011, (pp. 1-13).

GEOGEBRA. Downloads. Disponível em https://www.geogebra.org/download. Último acesso em 25.05.2017.

GEOGEBRA. GeoGebra tube. Disponível em https://www.geogebra.org/material/show/id/1303715 . Último acesso em 25.05.2017.

JAVARONI, S. L.; ZAMPIERI, M. T. O Uso das TIC nas Práticas dos Professores de Matemática da Rede Básica de Ensino: o projeto Mapeamento e seus desdobramentos. In: Bolema, Rio Claro (SP), v. 29, n. 53, p. 998-1022, 2015.

OLIVEIRA, F. T. A inviabilidade do uso das tecnologias da informação e comunicação no contexto escolar: o que contam os professores de Matemática? 2014. Dissertação de Mestrado (Educação Matemática) - Universidade Estadual Paulista, Instituto de Geociências e Ciências Exatas, Rio Claro, 2014.

OSTA, I. Computer technology and the teaching of Geometry. In: Perspectives on the Teaching of Geometry for the 21st century (New ICMI Study Series 5) (pp. 109-112), 1998.

PERALTA, P. F. Utilização das Tecnologias Digitais por Professores de Matemática: um olhar para a região de São José do Rio Preto. 119 f. 2015. Dissertação de Mestrado (Educação Matemática) - Universidade Estadual Paulista, Instituto de Geociências e Ciências Exatas, Rio Claro, 2015.

ROSA, M.; PAZUCH, V.; VANINI, L. Tecnologias no ensino de Matemática: a concepção de cyberformação como norteadora do processo educacional. Em: XI Encontro Gaúcho de Educação Matemática, Lajeado - RS. Anais ... p. 1 - 17, 2012.

SÃO PAULO. Acessa Escola. 2016. Disponível em http://www.educacao.sp.gov.br/acessa-escola . Último acesso em 31.08.2017

SÃO PAULO. Material de apoio ao currículo do estado de São Paulo. Caderno do professor. Matemática. Ensino Médio. v.2. 2014.

Secretaria da Educação do Estado de São Paulo. Portaria CGRH-3 de 9 de abril de 2015. Cronograma e diretrizes para atribuição de carga horária de Professor Auxiliar e do Projeto de Apoio Escolar. Disponível em https://nps9000.wordpress.com/2015/04/10/portaria-cgrh-3-de-9-4-2015-doe-de-1042015paa-2015/ . Último acesso em 31.08.2017.

SOUTO, D. L. Formação continuada on-line de professores de matemática: aspectos relativos ao design emergente de uma pesquisa. Em: Encontro brasileiro de estudantes de pós-graduação em Educação Matemática, 14, 2011. Anais... Campina Grande. p. 1-12 2011.

SILVA, A.; CHINELLATO, T. G.; ZAMPIERI, M. T.; JAVARONI, S. L. A inserção dos computadores nas aulas de matemática: perspectivas a partir de um estudo na cidade de Rio Claro. Em: II Congresso Nacional de formação de professores, 2014, Águas de Lindóia. Anais... [s.n.], 2014.

ZAMPIERI, M. T.; CHINELLATO, T. G.; JAVARONI, S. L. O projeto Mapeamento e a Insubordinação Criativa para o uso das tecnologias. Em: I International Conference of Creative Insubordination (ICOCIME). Anais...2017.

JAVARONI, S. L. Tecnologias digitais nas aulas de matemática: reflexões emergentes na formação continuada de professores. Em: XIII Encontro Paulista 
de Educação Matemática, São Paulo/Brasil. Anais: Conexões entre a prática docente e a pesquisa em Educação Matemática. [s.n.]. p. 1-9, 2017. . JAVARONI, S. L. SILVA, J. C. S. O uso das TIC nas aulas de Matemática: peculiaridades do Brasil, de Portugal e da França. Em: CIEMeLP: Conferência Internacional do Espaço Matemático em Língua Portuguesa, Coimbra. Anais... 2015.

JAVARONI, S. L.; SILVA, J. C. Formação continuada em ambientes de geometria dinâmica e seu impacto em sala de aula. Em: XXVII Seminário de Investigação em Educação Matemática (SIEM). Anais...Porto, 2016.

Submissão: 05/08/2017

Aceite: $26 / 11 / 2017$ 